\title{
Mapping landscape guidelines and principles to the Aichi targets
}

\author{
Reuben R Blackie ${ }^{1}$ and Terry $\mathrm{CH}$ Sunderland ${ }^{2}$
}

\section{Key Points}

- The 10 principles of a landscape approach are designed to assist managers in making decisions involving multiple or competing land uses.

- The principles were "taken note of" during the CBD COP in Hyderabad in 2011 and referenced as a valuable tool during the 17th SBSTTA meeting in Montreal, October 2013.

- The 17th SBSTTA also highlighted the complexity of land-management decisions and called for tools to assist parties in working toward the Aichi targets.

- Application of the principles has the potential to contribute to a number of the Aichi targets, particularly those under strategic goals $\mathrm{D}$ and $\mathrm{E}$.

- The next steps for the targets must be to generate greater awareness among parties, to demonstrate value and improve uptake.

The Aichi targets are central to global efforts to preserve biodiversity. These 20 targets, established by the UN Convention on Biodiversity (CBD), have a commitment until 2020 from 193 countries. The targets form a global strategic plan that aims to reduce the pressures on biodiversity, as well as improve its status and enhance its benefits (www.cbd.int)

As part of this, the CBD's Subsidiary Body on Scientific Technical and Technological Advice (SBSTTA), a team comprised of CIFOR and partner researchers, developed a set of 10 principles that were presented to the CBD Conference of the Parties (COP 11) in Hyderabad in 2011. ${ }^{3}$ The principles were designed to guide policy makers and assist practitioners in managing production and conservation trade-offs within the landscape, and the CBD officially "took note" of the principles at the negotiations. The principles were further elaborated in a peer-reviewed publication in the American Proceedings of the National Academy of Sciences (PNAS). ${ }^{4}$

Subsequent SBSTTA meetings in Montreal in 2013 and 2014 further highlighted the complexities in balancing oft-competing conservation and development objectives. Official documents from the 2013 meeting noted the need for improved use of landscape-scale

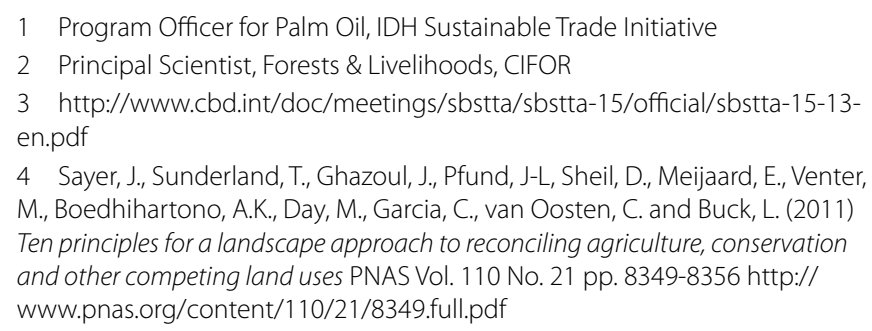

4 Sayer, J., Sunderland, T., Ghazoul, J., Pfund, J-L, Sheil, D., Meijaard, E., Venter, M., Boedhihartono, A.K., Day, M., Garcia, C., van Oosten, C. and Buck, L. (2011) Ten principles for a landscape approach to reconciling agriculture, conservation and other competing land uses PNAS Vol. 110 No. 21 pp. 8349-8356 http:// www.pnas.org/content/110/21/8349.full.pdf

approaches and made particular reference to the principles as a useful tool for contributing to the achievement of target $5 .^{5}$ This Infobrief explains how the 10 principles have the potential to contribute to the achievement of many more of the Aichi targets.

\section{How can the 10 principles contribute to achieving Aichi targets?}

The 10 landscape principles have been designed to assist in sustainably managing biodiversity within landscapes. As such, consistent application of the principles is relevant to all of the Aichi targets, depending on the manner and location in which they are applied. However, consistently applying guidelines is likely to contribute more to some targets than others. For example, implementing guidelines on a forestry project won't help achieve target 6 (sustainable management of fish stocks), but could still assist in achieving other non-location specific targets such as target 17 (development of policy instruments such as a biodiversity action plan). The following section explores each of the principles and identifies which target(s) they could best contribute toward.

\section{Principle 1: Continual learning and adaptive management}

This principle is particularly important to:

- Strategic Goal E

- Targets involving knowledge management such as 17,18 and $19^{6}$

\footnotetext{
5 https://www.cbd.int/doc/meetings/sbstta/sbstta-17/official/sbstta-17-02-en. pdf

6 See https://www.cbd.int/sp/targets/

for the goals and targets, which are also summarised in Annex 1.
} 
Table 1. Relevance of the 10 principles to Aichi strategic goals and targets

\begin{tabular}{lcl}
\hline Principle & $\begin{array}{l}\text { Aichi strategic } \\
\text { goal most likely } \\
\text { to benefit }\end{array}$ & $\begin{array}{l}\text { Aichi target(s) } \\
\text { most likely to } \\
\text { benefit }\end{array}$ \\
\hline $\begin{array}{l}\text { Adaptive learning and } \\
\text { management }\end{array}$ & $\mathrm{E}$ & $17,18,19$ \\
$\begin{array}{l}\text { Common concern entry point } \\
\text { Multiple scales }\end{array}$ & $\mathrm{E}$ & $4,17,18$ \\
$\begin{array}{l}\text { Multi-functionality } \\
\text { Multiple stakeholders }\end{array}$ & $\mathrm{A}$ & $2,4,11$ \\
$\begin{array}{l}\text { Negotiated, transparent } \\
\text { change logic }\end{array}$ & $\mathrm{E}$ & $4,14,15,16,19$ \\
$\begin{array}{l}\text { Clear rights and responsibilities } \\
\text { Participatory user-friendly }\end{array}$ & $\mathrm{D}$ & $1,14,17,18$ \\
monitoring & $\mathrm{A}, \mathrm{B}, \mathrm{D}$ & $4,14,16,18$ \\
$\begin{array}{l}\text { Resilience } \\
\text { Capacity building }\end{array}$ & $\mathrm{C}$ & $9,12,17,14,15$ \\
\hline
\end{tabular}

a See https://www.cbd.int/sp/targets/ for the goals and targets.

Since landscapes are complex, dynamic systems, management strategies need to be flexible enough to incorporate new knowledge and adapt to new circumstances. Targets 17-19 are most likely to benefit from adaptive management since these targets specifically involve knowledge and knowledge management. For example, the achievement of target 19 (improving and sharing knowledge of biodiversity) arguably depends on the application of adaptive management to ensure that knowledge of biodiversity remains up-to-date and worth sharing. Implementing principle 1 is also important for how systems are managed beyond the 2020 horizon. By reflecting on past experience, this principle ensures that new knowledge and approaches to conserving biodiversity continue to be incorporated into management strategies.

\section{Principle 2: Common concern entry point}

This principle is particularly important to:

- Strategic Goal E

- Targets involving multiple stakeholders such as 4,17 and 18

This principle is very general in its focus. The use of a common concern entry point is intended to help establish trust among stakeholders by prioritizing most achievable targets before moving toward more complex problems. Application of this principle is especially relevant to targets that specifically identify or involve multiple stakeholders, such as targets 4,17 and 18. Target 18, for example, involves incorporating indigenous access to resources into national legislation. However, this is likely to be a complex and politicized task, which will involve multiple stakeholders with different objectives and views. Therefore, applying the principle of a common concern entry point could help build trust and rapport between stakeholders before tackling the more complex problems required by the target.

\section{Principle 3: Multiple scales}

This principle is particularly important to:

- Strategic Goal A

- Targets involving different scales such as 2,4 and 11

The concept of multiple scales is essential to the landscape approach. Without considering the different scales that comprise a landscape, it is impossible to accurately understand relevant power structures and drivers of change affecting the landscape. At the project level, implementing this principle is likely to contribute to achieving many different targets, but particularly those that specifically deal with the need to address actors at different scales. These include targets 2, 4 and 11. For example, target 11 specifically calls for conservation areas to be linked and integrated into wider landscapes, which requires an understanding of the various processes operating at different scales.

\section{Principle 4: Multi-functionality}

This principle is particularly important to:

- Strategic Goal D

- Targets involving uses and benefits of biodiversity such as 4, 14, 15,16 and 19

Multi-functionality can be described as the co-existence of ecological, social and economic functions with the landscape. Applying this principle is particularly important for achieving targets 14-16 and 19, which deal explicitly with preserving services. Applying this principle can therefore assist in identifying those services and ensuring that any management plans take into account the multiple services and functions that different stakeholders obtain from landscapes. This principle could also benefit target 4, which involves the concept of multiple stakeholders and levels (which implies multiple functions).

\section{Principle 5: Multiple stakeholders}

This principle is particularly important to:

- Strategic Goal E

- Targets involving multiple stakeholders such as 4,14,17 and 18

A variety of stakeholders operate within different landscapes, each with different objectives, attitudes and needs. Principle 5 ensures that each stakeholder is considered (regardless of the degree of their involvement) during implementation. By incorporating this principle into management, projects can contribute to many Aichi targets. Target 4, in particular, requires action at multiple levels and between both private and public sectors, therefore requiring consideration of all stakeholders if it is to be effective. Similarly, targets 14 and 17-19 also require consideration of the needs of particular groups within society, and would therefore benefit from this principle being widely applied.

\section{Principle 6: Negotiated and transparent change logic}

This principle is particularly important to:

- Strategic Goal A

- Targets that require stakeholders to agree on the need for change, such as 1 and 4

The core of this principle focuses on ensuring there is clarity and trust among stakeholders. Applying this principle is important in achieving targets that explicitly identify action involving multiple stakeholders (see previous section). In particular, targets 1 and 4 would benefit from this principle since both require stakeholders to understand the need for change and support the process of change. For example, within target one, it will be difficult to ensure that people value and conserve biodiversity, if they do not agree with the logic behind the arguments that biodiversity is at risk.

Principle 7: Clarification of rights and responsibilities

This principle is particularly important to:

- Strategic Goal D

- Targets involving stakeholder cooperation such as 4, 14, 16 and 18 
Where multiple stakeholders are involved, respective rights and responsibilities must be clearly defined. In target 4, to implement steps toward sustainability, each stakeholder must recognize their expectations and those of others. Similarly, in target 14, by taking into account the needs of local communities, ecosystem services will be strengthened if those involved are aware of their own, and others', rights and responsibilities. Targets 16 and 18 can also only be applied effectively if people are aware of their rights. Implicit within these targets is the need for all stakeholders to accept and agree on the rights and responsibilities of each party.

\section{Principle 8: Participatory, user-friendly monitoring} This principle is particularly important to:

- Strategic Goal A, B, D

- Targets requiring stakeholders to report progress or agree a case for change such as targets 1, 2, 4, 17 and 18

While this is valuable in achieving all targets, it is especially important where high risk of conflict or distrust exists between stakeholders. Transparency and agreement on the gathering and use of information can help avoid alienating certain stakeholders. This is particularly important where evidence is required to make a case for change or in establishing compliance. Therefore, applying this principle can be especially useful to targets 1, 2, 4, 14, 16, 18 and 19 because these focus on stakeholder action for which poor monitoring could have significant negative impacts on trust and subsequent cooperation or participation. For target 6 , monitoring of fish stocks is a complex process. However, stakeholders that do not agree with the monitoring processes are unlikely to buy into management plans built on the results of that monitoring.

\section{Principle 9: Resilience}

This principle is particularly important to:

- Strategic Goal C

- Targets involving safeguarding systems such as $9,12,13$, 14 and 15

This principle focuses on actions that encourage resilience within ecosystems. Since resilience is essential to preserving biodiversity, this principle is again fundamental to all targets. However, targets 9, 12, 13,14 and 15 deal specifically with resilience; greater implementation of this principle, therefore, will be particularly beneficial to these targets. For example, developing an invasive species action plan for a particular ecosystem is one way to improve resilience, and would contribute directly to achieving target 9 .

\section{Principle 10: Strengthened stakeholder capacity}

This principle is particularly important to:

- Strategic Goal E

- Targets where capacity has been an issue in the past such as 1 , $14,17,18,19$ and 20

While all targets require adequate capacity, this is particularly important where weak capacity is known to be an issue. For example, weak capacity of indigenous people in negotiating legal frameworks that affect resource use in their vicinity is an issue globally. Therefore, this principle is particularly important where indigenous people are specifically identified within targets, such as targets 14 and 18. Furthermore, target 17 requires the formulation of a national biodiversity action plan. However, the capacity of different stakeholders to do this work will likely strongly affect the quality of different plans. Therefore, application of this principle could facilitate the achievement of this target.

\section{Next steps}

The SBSTTA Secretariat intends to hold a series of workshops in the run-up to the CBD COP 13, to be held in Los Cabos, Mexico in December 2016. Such meetings would be the ideal environment to raise the profile of the 10 principles for a landscape approach. Discussions between CIFOR and Secretariat staff have highlighted the importance of moving toward demonstrating real, practical examples of where the principles have been applied and have contributed to delivery of the targets. Although the PNAS paper notes the difficulty of locating sites and applying all the principles, it is also acknowledges that the framework is not a set of criteria that must be followed; sites demonstrating use of a few principles could be sufficient.

\section{Conclusions}

The 10 principles could greatly assist in contributing to the achievement of the CBD's Aichi targets. The principles are especially valuable in ensuring that multiple stakeholders at all scales are included to a sufficient degree within the decision making required to achieve the targets. All the targets and strategic goals can benefit from application of these guidelines. However, they have particular relevance to those that involve delivering multiple functions and dealing with multiple stakeholders such as those contained within strategic goals D and E.Recent SBSTTA meetings have demonstrated demand for tools such as the principles to help parties make decisions, particularly where multiple stakeholders are involved and integration between production and conservation landscapes is required. In the run-up to the CBD COP in 2016, the value of the principles should be demonstrated in real project applications to increase awareness and uptake.

\section{Aichi Strategic Goals and Targets}

Strategic Target 1 By 2020, at the latest, people are aware of the values of biodiversity and the steps they can take to conserve and use it Goal A sustainably.

Target 2 By 2020, at the latest, biodiversity values have been integrated into national and local development and poverty reduction strategies and planning processes and are being incorporated into national accounting, as appropriate, and reporting systems.

Target 3 By 2020, at the latest, incentives, including subsidies, harmful to biodiversity are eliminated, phased out or reformed in order to minimize or avoid negative impacts, and positive incentives for the conservation and sustainable use of biodiversity are developed and applied, consistent and in harmony with the convention and other relevant international obligations, taking into account national socioeconomic conditions.

Target 4 By 2020, at the latest, governments, business and stakeholders at all levels have taken steps to achieve or have implemented plans for sustainable production and consumption and have kept the impacts of use of natural resources well within safe ecological limits. 
Aichi Strategic Goals and Targets - Continued

Strategic Target 5 By 2020, the rate of loss of all natural habitats, including forests, is at least halved and where feasible brought close to Goal B zero, and degradation and fragmentation is significantly reduced.

Target 6 By 2020, all fish and invertebrate stocks and aquatic plants are managed and harvested sustainably, legally, and applying ecosystem-based approaches, so that overfishing is avoided, recovery plans and measures are in place for all depleted species, fisheries have no significant adverse impacts on threatened species and vulnerable ecosystems and the impacts of fisheries on stocks, species and ecosystems are within safe ecological limits.

Target 7 By 2020, areas under agriculture, aquaculture and forestry are managed sustainably, ensuring conservation of biodiversity.

Target 8 By 2020, pollution, including from excess nutrients, has been brought to levels that are not detrimental to ecosystem function and biodiversity.

Target 9 By 2020, invasive alien species and pathways are identified and prioritized, priority species are controlled or eradicated, and measures are in place to manage pathways to prevent their introduction and establishment.

Target 10 By 2015, the multiple anthropogenic pressures on coral reefs, and other vulnerable ecosystems impacted by climate change or ocean acidification are minimized, so as to maintain their integrity and functioning.

Strategic Target 11 By 2020, at least 17\% of terrestrial and inland water, and 10\% of coastal and marine areas, especially areas of Goal C particular importance for biodiversity and ecosystem services, are conserved through effectively and equitably managed, ecologically representative and well connected systems of protected areas and other effective area-based conservation measures, and integrated into the wider landscapes and seascapes.

Target 12 By 2020, the extinction of known threatened species has been prevented and their conservation status, particularly of those most in decline, has been improved and sustained.

Target 13 By 2020, the genetic diversity of cultivated plants and farmed and domesticated animals and of wild relatives, including other socioeconomically as well as culturally valuable species, is maintained, and strategies have been developed and implemented for minimizing genetic erosion and safeguarding their genetic diversity.

Strategic Target 14 By 2020, ecosystems that provide essential services, including services related to water, and contribute to health, Goal D livelihoods and well-being, are restored and safeguarded, taking into account the needs of women, indigenous and local communities, and the poor and vulnerable.

Target 15 By 2020, ecosystem resilience and the contribution of biodiversity to carbon stocks has been enhanced, through conservation and restoration, including restoration of at least $15 \%$ of degraded ecosystems, thereby contributing to climate change mitigation and adaptation and to combating desertification.

Target 16 By 2015, the Nagoya Protocol on Access to Genetic Resources and the Fair and Equitable Sharing of Benefits Arising from their Utilization is in force and operational, consistent with national legislation.

Strategic Target 17 By 2015, each party has developed, adopted as a policy instrument and commenced implementing an effective, Goal E participatory and updated national biodiversity strategy and action plan.

Target 18 By 2020, the traditional knowledge, innovations and practices of indigenous and local communities relevant for the conservation and sustainable use of biodiversity, and their customary use of biological resources, are respected, subject to national legislation and relevant international obligations, and fully integrated and reflected in the implementation of the convention with the full and effective participation of indigenous and local communities, at all relevant levels.

Target 19 By 2020, knowledge, the science base and technologies relating to biodiversity, its values, functioning, status and trends, and the consequences of its loss, are improved, widely shared and transferred, and applied.

Target 20 By 2020, at the latest, the mobilization of financial resources for effectively implementing the Strategic Plan for Biodiversity 2011-2020 from all sources, and in accordance with the consolidated and agreed process in the Strategy for Resource Mobilization, should increase substantially from the current levels. This target will be subject to changes contingent to resource needs assessments to be developed and reported by parties.

\section{\begin{tabular}{|l|l} 
CGIAR & $\begin{array}{l}\text { RESEARCH } \\
\text { PROGRAM ON }\end{array}$ \\
Forests, Trees and \\
Agroforestry
\end{tabular}}

This research was carried out by CIFOR as part of the CGIAR Research Program on Forests, Trees and Agroforestry (CRP-FTA). This collaborative program aims to enhance the management and use of forests, agroforestry and tree genetic resources across the landscape from forests to farms. CIFOR leads CRP-FTA in partnership with Bioversity International, CATIE, CIRAD, the International Center for Tropical Agriculture and the World Agroforestry Centre.

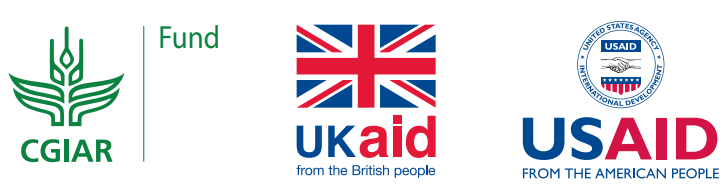

